\title{
Liver-Directed Radiotherapy for Hepatocellular Carcinoma
}

\author{
Florence K. Keane ${ }^{a} \quad$ Jennifer Y. Wo ${ }^{b}$ Andrew X. Zhu ${ }^{c}$ \\ Theodore S. Hong ${ }^{b}$ \\ aHarvard Radiation Oncology Program, Harvard Medical School \\ ${ }^{b}$ Department of Radiation Oncology, Massachusetts General Hospital \\ 'Division of Medical Oncology, Department of Medicine, Massachusetts General Hospital, Boston, \\ Mass., USA
}

\section{Key Words}

Hepatocellular carcinoma - Liver-directed radiotherapy · Stereotactic body radiotherapy

\begin{abstract}
:
Background: The incidence of hepatocellular carcinoma (HCC) continues to increase worldwide. Many patients present with advanced disease with extensive local tumor or vascular invasion and are not candidates for traditionally curative therapies such as orthotopic liver transplantation (OLT) or resection. Radiotherapy (RT) was historically limited by its inability to deliver a tumoricidal dose; however, modern RT techniques have prompted renewed interest in the use of liver-directed RT to treat patients with primary hepatic malignancies. Summary: The aim of this review was to discuss the use of external beam RT in the treatment of HCC, with particular focus on the use of stereotactic body radiotherapy (SBRT). We review the intricacies of SBRT treatment planning and delivery. Liver-directed RT involves accurate target identification, precise and reproducible patient immobilization, and assessment of target and organ motion. We also summarize the published data on liver-directed RT, and demonstrate that it is associated with excellent local control and survival rates, particularly in patients who are not candidates for OLT or resection. Key Messages: Modern liver-directed RT is safe and effective for the treatment of HCC, particularly in patients who are not candidates for OLT or resection. Liver-directed RT, including SBRT, depends on accurate target identification, precise and reproducible patient immobilization, and assessment of target and organ motion. Further prospective studies are needed to fully delineate the role of liver-directed RT in the treatment of HCC.

Copyright (C) 2016 S. Karger AG, Basel
\end{abstract}

Theodore S. Hong, MD

Department of Radiation Oncology, Massachusetts General Hospital 32 Fruit St, Yawkey 7, Boston, MA 02114 (USA)

Tel. +1 617726 6050, E-Mail TSHong1@mgh.harvard.edu 


\section{Introduction}

Hepatocellular carcinoma (HCC) is the second leading cause of cancer-related deaths worldwide, accounting for approximately 745,000 cases per year [1]. Many patients have advanced disease at the time of diagnosis and are therefore not candidates for curative-intent treatments, such as surgical resection, orthotopic liver transplantation (OLT) or radiofrequency ablation (RFA), because of the extent of the tumor or reduced hepatobiliary function. Outcomes are especially poor in patients with unresectable tumors and/or tumor venous involvement.

Currently, for patients with unresectable HCC who are not candidates for RFA, treatment options include systemic therapy, arterially directed therapies, and radiotherapy (RT) [2]. Liver-directed RT was historically limited to the palliative setting an inability to deliver a tumoricidal dose and concerns over hepatic tolerance; however, the development of modern RT techniques has made liver-directed RT a safe and effective option for many patients. Although there are no randomized data comparing these treatment modalities, multiple cohorts have demonstrated excellent local control rates associated with modern liver-directed RT. In this review, we discuss the development of modern liver-directed RT, with particular focus on stereotactic body radiotherapy (SBRT).

\section{Hepatic Tolerance and Conformal RT Techniques}

Liver-directed RT was historically limited by the lack of precise patient imaging, older RT techniques, and the inability to quantify and assess the dose received by a given volume of tissue. The RT treatment field often encompassed the entire liver. This necessitated the use of low doses of RT, which resulted in a low likelihood of tumor cure or control. Consequently, RT was primarily limited to the palliative setting $[3,4]$. The development of improved treatment planning and dose delivery methods, such as three-dimensional conformal radiation therapy and intensity-modulated radiation therapy, provided a mechanism not only to target hepatic lesions while sparing uninvolved hepatic parenchyma but also to precisely measure the radiation dose delivered to both the tumor volume and the surrounding normal tissue $[5,6]$. The development of conformal RT also provided a mechanism to treat lesions which were not candidates for RFA because of their location within the liver. Unlike RFA, SBRT is not limited by the location of the lesion and can be safely delivered to lesions in a variety of locations, including in the dome of the liver.

While the Emami report set general liver tolerance doses based on literature reports of toxicity [7], later studies provided more detailed assessment and guidelines regarding the risk of hepatotoxicity for given RT doses. At the University of Michigan, a series of doseescalation protocols of hyperfractionated conformal RT with concurrent hepatic arterial chemotherapy were used to calculate RT doses based on a maximum 10-15\% risk of radiation-induced liver disease (RILD) in patients with primary and metastatic hepatic lesions. These potential rates of RILD were calculated using a normal tissue complication probability (NTCP) model, which includes an effective volume (Veff) parameter that enables comparison of the dose received by a given volume of tissue for different RT plans. The NTCP model also includes the following parameters: the tolerance doses associated with a $50 \%$ chance of complications for uniform liver irradiation (TD50); $\mathrm{m}$, the steepness of the dose-response curve at TD50; and n, which quantifies the impact of the volume irradiated. Because patients with primary hepatobiliary disease have increased susceptibility to radiation-induced toxicity, doses were also adjusted based on whether patients had primary hepatic tumors or metastatic lesions. In this series, patients with unresectable HCC had a median survival of 
15.2 months. Of note, the subset of patients who received a dose to the tumor $\geq 75$ Gy had an improvement in overall survival (OS) on multivariate analysis (23.9 months vs. 14.9 months, $\mathrm{p}<0.01$ ) [8].

\section{SBRT: Treatment Planning}

The use of liver-directed RT significantly increased with the development of SBRT. SBRT uses multiple conformal beams to deliver high doses of RT with rapid dose fall-off beyond the target volume. While the complete mechanism underlying SBRT-induced cell death is still a topic of research, the high radiation doses in SBRT are thought to result in an ablative effect on the tumor through vascular injury, in addition to the DNA damage and cell death seen in conventionally fractionated RT [9-15]. Given the highly conformal nature of SBRT, precise tumor definition and dose delivery are imperative. In addition to sophisticated treatment planning software systems, SBRT also depends on accurate target identification, precise and reproducible patient immobilization, and assessment of target and organ motion.

\section{Target Identification}

The safety and efficacy of conformal RT depend on precise delineation of the target volume, both to ensure adequate tumor coverage and to spare the maximal amount of normal hepatic parenchyma. The patterns of enhancement in HCC on both computed tomography (CT) and magnetic resonance imaging (MRI) have been previously described. Classically, HCC is characterized by arterial enhancement with washout on delayed venous phases $[16,17]$. On MRI, small HCC lesions tend to be isointense with rapid contrast enhancement, but larger HCC nodules may instead appear T1 hypointense and T2 hyperintense [18, 19].

However, individual tumors can have variable enhancement on multiphasic CT. Use of only one phase when contouring can lead to misidentification of normal hepatic parenchyma or vasculature as tumor [20] or can lead to undercontouring and a geographic miss. Consequently, the Radiation Therapy Oncology Group (RTOG) consensus guidelines for HCC target definition recommend using the union of gross tumor volumes (GTVs) as contoured across multiphasic imaging, noting heterogeneity in target definition in three representative HCC cases [20]. In our recent study on the impact of intravenous contrast enhancement on target definition in HCC, we found that there was no consistent phase that provided optimal tumor visualization. Moreover, this uncertainty could not be overcome with a uniform expansion around either the smallest, largest, or best visualized gross tumor volume (GTV) [21]. These results also support the RTOG recommendation for using the union of GTVs across all available phases of multiphasic imaging.

It is also important to note that multiphasic CT requires precise timing of contrast infusion with imaging, which may be difficult to achieve in radiation oncology departments. At our institution, diagnostic radiology uses the following timing for multiphasic diagnostic CT: arterial phase images are obtained immediately after the aortic peak, or 30-35s after contrast infusion; portal venous phase images are obtained $45 \mathrm{~s}$ after peak aortic enhancement, as determined by bolus tracking; and delayed phase images are obtained approximately $3 \mathrm{~min}$ after portal venous phase images. Tumor enhancement can vary across phases, as some tumors may be visible on the late arterial phase, but not on the early arterial phase or vice-versa of a CT scan [21].

Contouring is particularly challenging in the setting of tumor vascular involvement or infiltrative lesions. For example, there was significant interobserver variability among 11 gastrointestinal radiation oncologists when attempting to define vascular GTV in the setting of 
portal venous invasion [20]. Accurate definition of the full extent of vascular involvement of the tumor is essential for adequate local control and patient survival, because progression of vascular involvement can lead to significant decline in hepatobiliary function.

For some patients, including those with infiltrative lesions, the hepatic tumor may be visible on MRI but not easily identified on CT. In such cases, incorporating liver MRIs into treatment planning may be helpful. However, this then introduces the need for CT-MRI fusion, which can in turn increase uncertainty. There can also be significant organ deformation between different series, leading to poor fusion. The recent RTOG series on interobserver variability in contouring noted that suboptimal MR-CT fusion can lead to significant target overcontouring [20]. Placement of MR-compatible fiducials and obtaining the MRI in the RT treatment position may facilitate fusion, but all registrations must be rigorously assessed. Of note, some institutions have MR-based simulation for RT planning, but these systems are not yet widely available.

\section{Patient Immobilization}

RT planning and dose delivery occur on different days and require the patient to lie in the same position for a prolonged period of time each day. Therefore, immobilization devices are needed to ensure that patients remain in a consistent, reproducible position throughout treatment. Immobilization is particularly challenging in the treatment of extracranial lesions. At our institution, custom immobilization is designed for each patient at the time of RT planning. Immobilization devices include vacuum bags or thermoplastic devices, with or without a body frame [22].

\section{Organ and Target Motion}

Organ and target motion also complicate treatment delivery. The liver is particularly affected by changes in breathing motion. Multiple strategies are implemented to both assess and compensate for organ and target motion. First, patients undergo CT-guided placement of at least three fiducial markers in the normal hepatic parenchyma around the lesion prior to CT simulation. These markers are essential for accurate patient setup and treatment delivery. For lesions that are close to bowel, we also favor placement of a biologic mesh spacer, which has been shown to sufficiently displace bowel to allow safe administration of RT [23].

We do not recommend the use of free-breathing CT for RT planning as this will not provide adequate information on tumor motion over the course of the respiratory cycle and may result in a geographic miss. Instead, all patients have a four-dimensional (4D) CT [24] consisting of ten individual CT scans obtained throughout the respiratory cycle. Target motion is assessed to ensure accurate coverage of the tumor. The motion of the target is also compared to the movement of the fiducial markers [24-26].

In patients with significant target motion, as identified on 4D-CT, active breathing control $[27,28]$ or abdominal compression [29-32] may help to reduce both organ and target motion. It is noteworthy that the efficacy of abdominal compression varies between studies - while some have demonstrated significant decreases in organ motion with abdominal compression [24], others have shown small changes which were not clinically significant [30]. There is also a degree of organ deformation from abdominal compression; however, this is typically small [33].

Active breathing control has been used with both photon [34, 35] and proton [36] liverdirected RT. In active breathing control [31], or respiratory gating, RT is delivered only during certain phases of the respiratory cycle. Respiratory gating typically requires tracking of the respiratory cycle throughout treatment, as well as patient breath hold. Active breathing control has improved intrafraction variability, but there may be persistent interfraction variability [35, 37]. 


\section{Treatment Delivery}

Treatment delivery varies based on the type of RT delivered and on a given center's brand of linear accelerator. Cyberknife ${ }^{\circledR}$ employs real-time orthogonal X-ray tracking of implanted fiducial markers. Alternatively, onboard cone-beam CTs, such as those on the Varian Trilogy ${ }^{\circledR}$ and the Elekta Synergy ${ }^{\circledR}$, can be used before treatment, between treatment fields, and after completion of treatment. With both forms of treatment delivery, fiducial markers are essential to ensure accurate patient setup and treatment delivery. Alignment based solely on bony anatomy may lead to errors in patient setup.

As with all oncologic treatments, care must be taken to carefully monitor clinical status prior to, and during, the course of liver-directed RT, because many patients with HCC have poor hepatobiliary function. With a decline in hepatobiliary function, these patients may develop or have worsening ascites, which can in turn result in a significant change in the position of the liver and the target. Patients with discrepancies in target or fiducial position between the planning CT and the pretreatment cone-beam CT may require repeated RT planning.

\section{Outcomes of SBRT}

\section{Overview}

While there have been no prospective randomized trials of SBRT published to date, multiple retrospective and prospective Phase I and Phase II studies have demonstrated the safety and efficacy of SBRT. At 1 year, local control rates range from 64 to $100 \%$, and OS ranges from 48 to $100 \%$ [28, 38-49]. These results are particularly impressive given the number of patients included in these studies who had advanced disease and had failed prior therapies. For example, in a phase I study of SBRT in 31 patients with unresectable HCC at Princess Margaret Cancer Centre, there were no cases of RILD or treatment-related grade $\geq 4$ toxicity, and median survival was 13.4 months [28]. Outcomes are particularly impressive in patients with early stage tumors $[38,39,50]$, with 1-year local control rates of $95-100 \%$ and 1-year OS rates of $99-100 \%$ seen in two series of SBRT for tumors measuring $1-5 \mathrm{~cm}[38,39]$. SBRT has also been shown to be well tolerated in prospective studies assessing quality-of-life metrics [51]. Table 1 provides additional details on prospective and retrospective studies of liver-directed SBRT [28, 38-47, 49, 50, 52-60].

These studies included many patients who had failed prior treatments, including arterially directed therapies. Transarterial chemoembolization (TACE) and transarterial embolization are common treatments for patients with unresectable lesions that are not appropriate for ablative techniques. However, the available randomized data compare arterially directed therapies only to supportive care [61-64], and local control and survival remain poor. In the majority of published series, RT was used as salvage after the failure of arterially directed therapies. For example, one series of 398 patients included 312 patients who had previously received at least one course of TACE [65]. There were no grade $\geq 3$ toxicities, and median survival was 12 months. This cohort included 88 patients with Child-Pugh (CP) B cirrhosis. Salvage RT after TACE has also demonstrated impressive rates of local control, with an overall response rate (ORR) of $83.9 \%$ and a complete response rate of $22.6 \%$ [66].

It is noteworthy that these studies have treated patients with a variety of doses and fractionation schemes. The optimal dose for HCC is not yet known. Several studies have reported improved outcomes in patients treated with higher doses of RT [45]. For example, in a series of 82 patients with HCC tumors measuring up to $7 \mathrm{~cm}$ (median $3.0 \mathrm{~cm}$ ), local control at 4.5 years was $100 \%$ and OS at 4.5 years was $68 \%$ in patients who received SBRT total doses $\geq 54$ Gy. None of these patients developed classic RILD [45]. However other studies have also dem- 


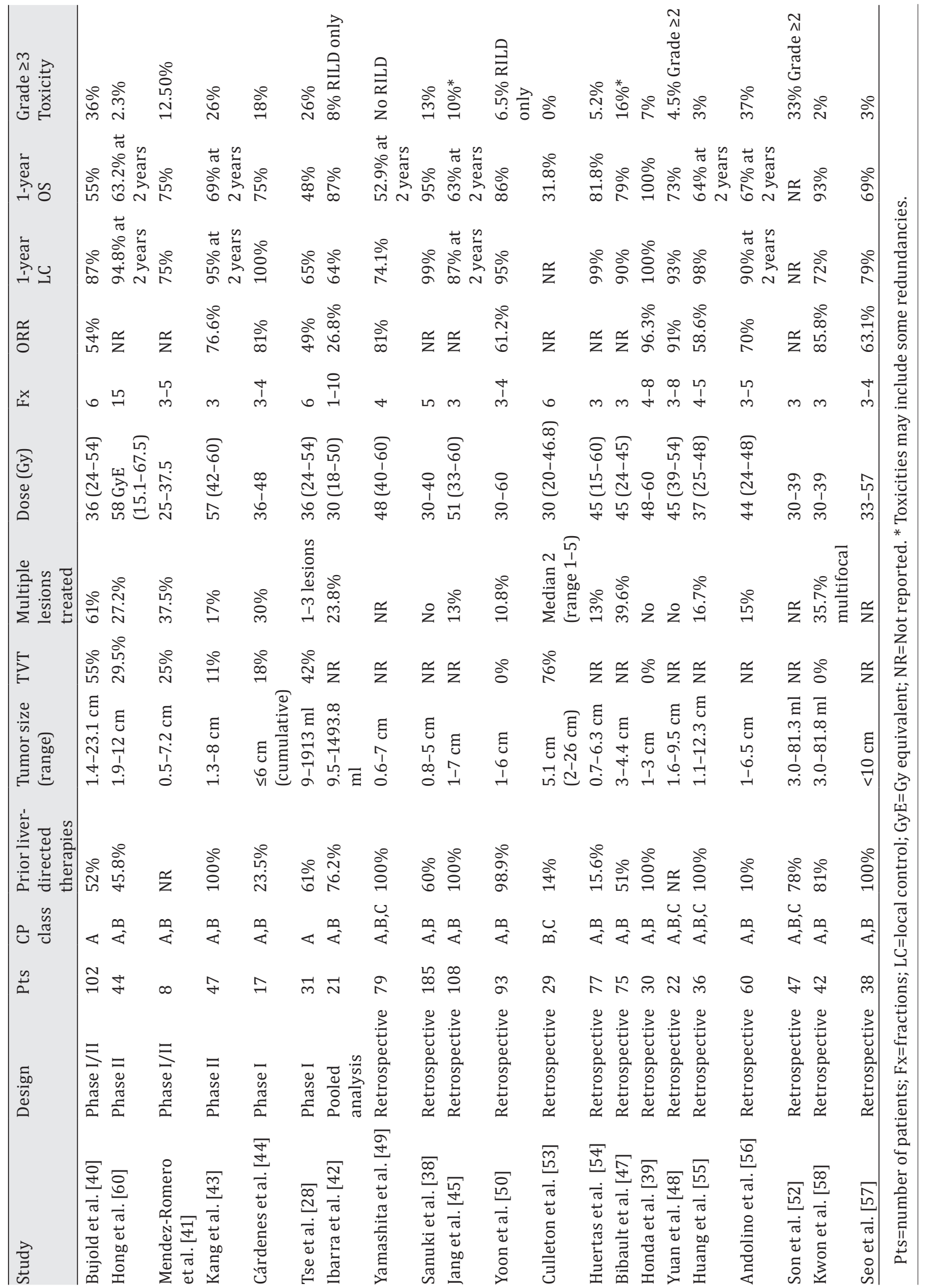




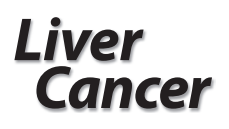

Liver Cancer 2016;5:198-209

DOI: $10.1159 / 000367764$

Published online: May 10, 2016

2016 S. Karger AG, Basel

Keane et al.: Liver-Directed RT for HCC

onstrated responses with lower doses of RT $[38,53]$. For patients with small primary tumors, treatment with lower doses of RT gives excellent control. For example, Sanuki et al. reported a series of 185 patients with 0.8 - to 5-cm lesions who were treated with SBRT at 30-40 Gy in five fractions with 3-year rates of local control of $91 \%$ and 3-year rates of OS of 70\% [38]. The impressive results seen with lower doses of RT are particularly important because many patients who are referred for liver SBRT already have compromised hepatobiliary function, including those in a prospective study of patients with CP Class B or C cirrhosis who were treated to a median dose of 30 Gy in six fractions [53].

\section{SBRT for HCC with Tumor Vein Thrombosis (TVT)}

Outcomes are particularly poor in patients with HCC with TVT. The median survival of untreated patients is 2-4 months [67]. Portal TVT is often a contraindication to arterially directed therapies and has been associated with increased risk of mortality on multivariate analysis (odds ratio 3.24, $\mathrm{p}=0.013$ ) [63]. Outcomes also decline in patients with portal vein thrombosis who are treated with transarterial radioembolization or selective internal radiation therapy (SIRT). In a prospective cohort study, median survival was 5.6 months in patients with $\mathrm{CP}$ B cirrhosis and portal vein thrombosis versus 17.2 months in patients with $\mathrm{CP}$ A cirrhosis [68]. Furthermore, TVT can result in further alteration of the vasculature in HCC, thereby interfering with effective dose delivery in SIRT. Unlike arterially directed therapies, RT does not depend on preserved hepatic vasculature and has been safely delivered in numerous patients with TVT.

Several reported series have used RT for patients with HCC with TVT. Response rates ranged from 50 to $79 \%$ and median OS ranged from 3.8 to 22 months [40, 46, 69-74]. Yoon et al. reported a series of 412 patients with HCC with portal TVT, of whom 200 had involvement of the main portal vein or bilateral portal vein. Patients were treated to a median dose of $40 \mathrm{~Gy}$ in two to five fractions directed to the thrombosis in conjunction with TACE. Progression-free survival was $85.6 \%$, 1-year OS was $42.5 \%$, and median OS was $10.6 \%$ [46]. Of note, several of the series used RT to treat the tumor thrombus only, instead of treating both the TVT and the intrahepatic disease. With the improved techniques of modern liver-directed RT, treatment of the full extent of disease has become feasible. For example, Sugahara et al. noted a significant increase in OS in patients who received proton RT to both the portal TVT and intrahepatic disease compared with those patients who received treatment directed at the TVT only [69].

We do not recommend the off-study treatment of patients with CP C cirrhosis, because these patients have a significant mortality risk as a result of their poor hepatic function. There are, unfortunately, no effective treatment options for these patients, because TACE is contraindicated and RT has not shown a survival benefit in retrospective series.

\section{Charged Particle Therapy}

\section{Background}

Charged particle therapy has also been employed in the treatment of hepatic tumors. Unlike photon-based RT, which has an exponential dose fall-off, particle-based therapy (such as proton therapy) has an extremely rapid dose fall-off at the end of its range. Specifically, when protons enter tissue, the beam loses small amounts of energy until reaching the end of its range, when energy deposition sharply increases, with energy deposition occurring over a short distance. This area, or the Bragg peak, measures approximately $0.7 \mathrm{~cm}$ in width at $80 \%$ of the maximum dose. As $0.7 \mathrm{~cm}$ is not a large enough area to cover the majority of lesions, different techniques are employed to ensure adequate tumor coverage. These include pas- 
sive scattering (single or double scattering), with a range modulators employed to create a "spread-out" Bragg peak. Other techniques include pencil-beam scanning, which does not require scattering. The rapid dose fall-off of proton therapy may enable greater sparing of normal hepatic parenchyma, while still delivering a tumoricidal dose to the hepatic lesion. Wang et al. compared proton and photon plans for the same hepatic lesions and found that the proton plans were associated with lower mean hepatic doses, lower stomach dose, and lower maximum spinal cord dose [75]. A study of carbon-ion therapy also showed improvements in target coverage and sparing of normal tissue when compared to photon RT [76].

\section{Outcomes of Charged Particle Therapy}

Similarly to SBRT, there are currently no randomized prospective data comparing charged particle therapy to other treatment modalities. Retrospective data, including a series of 318 patients treated at the University of Tsukuba with a $44.6 \%$ OS rate at 5 years [77], have shown that charged particle therapy can be delivered safely and effectively in selected patients. Bush et al. published a phase II study of high-dose proton therapy and found that, despite the inclusion of several patients with advanced disease (including $54 \%$ of patients with disease outside the Milan criteria), the median progression-free survival was 36 months, with no grade $\geq 3$ toxicities [78]. Prospective trials are ongoing.

\section{Conclusions}

As a result of numerous advancements in the field of RT, liver-directed RT is now a safe and effective treatment for patients with HCC. Many of the critiques of liver-directed RT are based on historical reports of toxicity in patients treated with outdated techniques and do not reflect the current status of the field. Tumoricidal doses of RT can now be safely delivered with excellent local control and minimal toxicity. We recommend consideration of SBRT in patients with early-stage HCC who are not candidates for OLT, surgical resection, or RFA, such as patients with one or a few lesions measuring 3-6 cm. Furthermore, if there is a sufficient volume of normal hepatic parenchyma, patients with larger tumors $(6-10 \mathrm{~cm}) \mathrm{can}$ also be treated safely with liver-directed RT.

Further study is needed to determine the optimal treatment for patients with unresectable HCC who are not candidates for ablative therapies. Liver-directed RT should be a focus of this research, as the ideal treatment regimen for patients may consist of liver-directed RT in concert with systemic therapies or with arterially directed therapies. Therefore, we strongly recommend protocol enrollment for patients whenever possible. RTOG 1112 [79] is a Phase III trial of sorafenib with or without SBRT in patients with unresectable Barcelona Clinic Liver Cancer (BCLC) stage B (intermediate) or C (advanced) HCC who are not candidates for RFA or TACE or who were refractory to TACE. This study will provide important data on the role of SBRT in patients with advanced HCC. It is noteworthy that patients with vascular involvement and large tumors (tumor occupying up to $40 \%$ of the liver volume) are eligible for enrollment and will be stratified within the two study arms. Patients with portal vein thrombosis are often excluded from trials, so sorafenib with SBRT represents an important potential treatment option for this patient population. A Phase III trial at Loma Linda University Medical Center is randomizing patients to TACE versus proton beam RT [80]. Finally, a study in Singapore of patients with BCLC stage B and C HCC will randomize patients to sorafenib versus SIRT with SIR-Spheres (SIRTex Medical, Lake Forest, IL, USA) [81]. Patients with complete main portal vein thrombosis are not candidates for this protocol. 
In summary, liver-directed RT is an important treatment modality for patients with HCC and should be integrated into treatment paradigms. Prospective studies are needed to determine the optimal treatment regimens for patients with advanced HCC.

\section{Financial Disclosures}

The authors have no financial disclosures to declare.

\section{References}

1 Siegel RL, Miller KD, Jemal A: Cancer statistics, 2015. CA Cancer J Clin 2015;65:5-29.

2 National Comprehensive Cancer Network: Hepatobiliary Cancers (Version 2.2014). http://www.nccn.org/ professionals/physician_gls/pdf/hepatobiliary.pdf.

3 Borgelt BB, Gelber R, Brady LW, Griffin T, Hendrickson FR: The palliation of hepatic metastases: results of the Radiation Therapy Oncology Group pilot study. Int J Radiat Oncol Biol Phys 1981;7:587-591.

4 Russell AH, Clyde C, Wasserman TH, Turner SS, Rotman M: Accelerated hyperfractionated hepatic irradiation in the management of patients with liver metastases: results of the RTOG dose escalating protocol. Int J Radiat Oncol Biol Phys 1993;27:117-123.

5 McGinn CJ, Ten Haken RK, Ensminger WD, Walker S, Wang S, Lawrence TS: Treatment of intrahepatic cancers with radiation doses based on a normal tissue complication probability model. J Clin Oncol 1998;16:2246-2252.

6 Dawson LA, McGinn CJ, Normolle D, Ten Haken RK, Walker S, Ensminger W, Lawrence TS: Escalated focal liver radiation and concurrent hepatic artery fluorodeoxyuridine for unresectable intrahepatic malignancies. J Clin Oncol 2000;18:2210-2218.

7 Emami B, Lyman J, Brown A, Coia L, Goitein M, Munzenrider JE, Shank B, Solin LJ, Wesson M: Tolerance of normal tissue to therapeutic irradiation. Int J Radiat Oncol Biol Phys 1991;21:109-122.

8 Ben-Josef E, Normolle D, Ensminger WD, Walker S, Tatro D, Ten Haken RK, Knol J, Dawson LA, Pan C, Lawrence TS: Phase II trial of high-dose conformal radiation therapy with concurrent hepatic artery floxuridine for unresectable intrahepatic malignancies. J Clin Oncol 2005;23:8739-8747.

9 Song CW, Cho LC, Yuan J, Dusenbery KE, Griffin RJ, Levitt SH: Radiobiology of stereotactic body radiation therapy/stereotactic radiosurgery and the linear-quadratic model. Int J Radiat Oncol Biol Phys 2013;87:1819.

10 Song CW, Kim MS, Cho LC, Dusenbery K, Sperduto PW: Radiobiological basis of SBRT and SRS. Int J Clin Oncol 2014;19:570-578.

11 Kocher M, Treuer H, Voges J, Hoevels M, Sturm V, Müller RP: Computer simulation of cytotoxic and vascular effects of radiosurgery in solid and necrotic brain metastases. Radiother Oncol 2000;54:149-156.

12 Park C, Papiez L, Zhang S, Story M, Timmerman RD: Universal survival curve and single fraction equivalent dose: useful tools in understanding potency of ablative radiotherapy. Int J Radiat Oncol Biol Phys 2008;70:847-852.

13 Brown JM, Carlson DJ, Brenner DJ: The tumor radiobiology of SRS and SBRT: are more than the 5 Rs involved? Int J Radiat Oncol Biol Phys 2014;88:254-262.

14 Pan T, Lee TY, Rietzel E, Chen GT: 4D-CT imaging of a volume influenced by respiratory motion on multislice CT. Med Phys 2004;31:333-340.

15 Rietzel E, Chen GT, Choi NC, Willet CG: Four-dimensional image-based treatment planning: Target volume segmentation and dose calculation in the presence of respiratory motion. Int J Radiat Oncol Biol Phys 2005;61:1535-1550.

16 Araki T, Itai Y, Furui S, Tasaka A: Dynamic CT densitometry of hepatic tumors. AJR Am J Roentgenol 1980;135:1037-1043.

17 Baron RL, Oliver JH 3rd, Dodd GD 3rd, Nalesnik M, Holbert BL, Carr B: Hepatocellular carcinoma: evaluation with biphasic, contrast-enhanced, helical CT. Radiology 1996;199:505-511.

18 Rummeny E, Weissleder R, Stark DD, Saini S, Compton CC, Bennett W, Hahn PF, Wittenberg J, Malt RA, Ferrucci JT: Primary liver tumors: diagnosis by MR imaging. AJR Am J Roentgenol 1989;152:63-72.

19 Yamashita Y, Hatanaka Y, Yamamoto H, Arakawa A, Matsukawa T, Miyazaki T, Takahashi M: Differential diagnosis of focal liver lesions: role of spin-echo and contrast-enhanced dynamic MR imaging. Radiology 1994;193:59-65.

20 Hong TS, Bosch WR, Krishnan S, Kim TK, Mamon HJ, Shyn P, Ben-Josef E, Seong J, Haddock MG, Cheng JC, Feng MU, Stephans KL, Roberge D, Crane C, Dawson LA: Interobserver variability in target definition for hepatocellular carcinoma with and without portal vein thrombus: radiation therapy oncology group consensus guidelines. Int J Radiat Oncol Biol Phys 2014;89:804-813. 
21 Niska JR, Keane FK, Wolfgang JA, Hahn PF, Wo JY, Zhu AX, Hong TS: Impact of intravenous contrast enhancement phase on target definition for hepatocellular carcinoma (HCC) and intrahepatic cholangiocarcinoma (IHC): Observations from patients enrolled on a prospective phase 2 trial. Pract Radiat Oncol 2016;6:e9-e16.

22 Lo SS, Fakiris AJ, Chang EL, Mayr NA, Wang JZ, Papiez L, Teh BS, McGarry RC, Cardenes HR, Timmerman RD: Stereotactic body radiation therapy: a novel treatment modality. Nat Rev Clin Oncol 2010;7:44-54.

23 Yoon SS, Aloia TA, Haynes AB, Kambadakone A, Kaur H, Vauthey JN, Ferrone CR, Zhu AX, Wo JY, Crane C, Hong TS: Surgical placement of biologic mesh spacers to displace bowel away from unresectable liver tumors followed by delivery of dose-intense radiation therapy. Pract Radiat Oncol 2014;4:167-173.

24 Heinzerling JH, Anderson JF, Papiez L, Boike T, Chien S, Zhang G, Abdulrahman R, Timmerman R: Four-dimensional computed tomography scan analysis of tumor and organ motion at varying levels of abdominal compression during stereotactic treatment of lung and liver. Int J Radiat Oncol Biol Phys 2008;70:15711578.

25 Lax I, Blomgren H, Näslund I, Svanström R: Stereotactic radiotherapy of malignancies in the abdomen. Methodological aspects. Acta Oncol 1994;33:677-683.

26 Langen KM, Jones DT: Organ motion and its management. Int J Radiat Oncol Biol Phys 2001;50:265-278.

27 Blomgren H, Lax I, Näslund I, Svanström R: Stereotactic high dose fraction radiation therapy of extracranial tumors using an accelerator. Clinical experience of the first thirty-one patients. Acta Oncol 1995;34:861-870.

28 Tse RV, Hawkins M, Lockwood G, Kim JJ, Cummings B, Knox J, Sherman M, Dawson LA: Phase I study of individualized stereotactic body radiotherapy for hepatocellular carcinoma and intrahepatic cholangiocarcinoma. J Clin Oncol 2008;26:657-664.

29 Case RB, Sonke JJ, Moseley DJ, Kim J, Brock KK, Dawson LA: Inter- and intrafraction variability in liver position in non-breath-hold stereotactic body radiotherapy. Int J Radiat Oncol Biol Phys 2009;75:302-308.

30 Eccles CL, Patel R, Simeonov AK, Lockwood G, Haider M, Dawson LA: Comparison of liver tumor motion with and without abdominal compression using cine-magnetic resonance imaging. Int J Radiat Oncol Biol Phys 2011;79:602-608.

31 Wong JW, Sharpe MB, Jaffray DA, Kini VR, Robertson JM, Stromberg JS, Martinez AA: The use of active breathing control (ABC) to reduce margin for breathing motion. Int J Radiat Oncol Biol Phys 1999;44:911919.

32 Dawson LA, Ten Haken RK, Lawrence TS: Partial irradiation of the liver. Semin Radiat Oncol 2001;11:240246.

33 Eccles CL, Dawson LA, Moseley JL, Brock KK: Interfraction liver shape variability and impact on GTV position during liver stereotactic radiotherapy using abdominal compression. Int J Radiat Oncol Biol Phys 2011;80:938-946.

34 Dawson LA, Eccles C, Craig T: Individualized image guided iso-NTCP based liver cancer SBRT. Acta Oncol 2006;45:856-864.

35 Dawson LA, Brock KK, Kazanjian S, Fitch D, McGinn CJ, Lawrence TS, Ten Haken RK, Balter J: The reproducibility of organ position using active breathing control $(\mathrm{ABC})$ during liver radiotherapy. Int J Radiat Oncol Biol Phys 2001;51:1410-1421.

36 Hong TS, DeLaney TF, Mamon HJ, Willett CG, Yeap BY, Niemierko A, Wolfgang JA, Lu HM, Adams J, Weyman EA, Arellano RS, Blaszkowsky LS, Allen JN, Tanabe KK, Ryan DP, Zhu AX: A prospective feasibility study of respiratory-gated proton beam therapy for liver tumors. Pract Radiat Oncol 2014;4:316-322.

37 Eccles C, Brock KK, Bissonnette JP, Hawkins M, Dawson LA: Reproducibility of liver position using active breathing coordinator for liver cancer radiotherapy. Int J Radiat Oncol Biol Phys 2006;64:751-759.

38 Sanuki N, Takeda A, Oku Y, Mizuno T, Aoki Y, Eriguchi T, Iwabuchi S, Kunieda E: Stereotactic body radiotherapy for small hepatocellular carcinoma: a retrospective outcome analysis in 185 patients. Acta Oncol 2014;53:399-404.

39 Honda Y, Kimura T, Aikata H, Kobayashi T, Fukuhara T, Masaki K, Nakahara T, Naeshiro N, Ono A, Miyaki D, Nagaoki Y, Kawaoka T, Takaki S, Hiramatsu A, Ishikawa M, Kakizawa H, Kenjo M, Takahashi S, Awai K, Nagata Y, Chayama K: Stereotactic body radiation therapy combined with transcatheter arterial chemoembolization for small hepatocellular carcinoma. J Gastroenterol Hepatol 2013;28:530-536.

40 Bujold A, Massey CA, Kim JJ, Brierley J, Cho C, Wong RK, Dinniwell RE, Kassam Z, Ringash J, Cummings B, Sykes J, Sherman M, Knox JJ, Dawson LA: Sequential phase I and II trials of stereotactic body radiotherapy for locally advanced hepatocellular carcinoma. J Clin Oncol 2013;31:1631-1639.

41 Méndez Romero A, Wunderink W, Hussain SM, De Pooter JA, Heijmen BJ, Nowak PC, Nuyttens JJ, Brandwijk RP, Verhoef C, Ijzermans JN, Levendag PC: Stereotactic body radiation therapy for primary and metastatic liver tumors: A single institution phase i-ii study. Acta Oncol 2006;45:831-837.

42 Ibarra RA, Rojas D, Snyder L, Yao M, Fabien J, Milano M, Katz A, Goodman K, Stephans K, El-Gazzaz G, Aucejo F, Miller C, Fung J, Lo S, Machtay M, Sanabria JR: Multicenter results of stereotactic body radiotherapy (SBRT) for non-resectable primary liver tumors. Acta Oncol 2012;51:575-583.

43 Kang JK, Kim MS, Cho CK, Yang KM, Yoo HJ, Kim JH, Bae SH, Jung H, Kim KB, Lee DH, Han CJ, Kim J, Park SC, Kim YH: Stereotactic body radiation therapy for inoperable hepatocellular carcinoma as a local salvage treatment after incomplete transarterial chemoembolization. Cancer 2012;118:5424-5431.

44 Cárdenes HR, Price TR, Perkins SM, Maluccio M, Kwo P, Breen TE, Henderson MA, Schefter TE, Tudor K, Deluca J, Johnstone PA: Phase I feasibility trial of stereotactic body radiation therapy for primary hepatocellular carcinoma. Clin Transl Oncol 2010;12:218-225. 
45 Jang WI, Kim MS, Bae SH, Cho CK, Yoo HJ, Seo YS, Kang JK, Kim SY, Lee DH, Han CJ, Kim J, Park SC, Kim SB, Cho EH, Kim YH: High-dose stereotactic body radiotherapy correlates increased local control and overall survival in patients with inoperable hepatocellular carcinoma. Radiat Oncol 2013;8:250.

46 Yoon SM, Lim YS, Won HJ, Kim JH, Kim KM, Lee HC, Chung YH, Lee YS, Lee SG, Park JH, Suh DJ: Radiotherapy plus transarterial chemoembolization for hepatocellular carcinoma invading the portal vein: long-term patient outcomes. Int J Radiat Oncol Biol Phys 2012;82:2004-2011.

47 Bibault JE, Dewas S, Vautravers-Dewas C, Hollebecque A, Jarraya H, Lacornerie T, Lartigau E, Mirabel X: Stereotactic body radiation therapy for hepatocellular carcinoma: prognostic factors of local control, overall survival, and toxicity. PLoS ONE 2013;8:e77472.

48 Yuan Z, Tian L, Wang P, Song Y, Dong Y, Zhuang H: Comparative research on the efficacy of CyberKnife $®$ and surgical excision for Stage I hepato cellular carcinoma. Onco Targets Ther 2013;6:1527-1532.

49 Yamashita H, Onishi H, Murakami N, Matsumoto Y, Matsuo Y, Nomiya T, Nakagawa K, Japanese Radiological Society multi-institutional SBRT study group (JRS-SBRTSG): Survival outcomes after stereotactic body radiotherapy for 79 Japanese patients with hepatocellular carcinoma. J Radiat Res (Tokyo) 2015;56:561-567.

50 Yoon SM, Lim YS, Park MJ, Kim SY, Cho B, Shim JH, Kim KM, Lee HC, Chung YH, Lee YS, Lee SG, Lee YS, Park $\mathrm{JH}, \mathrm{Kim} \mathrm{JH}$ : Stereotactic body radiation therapy as an alternative treatment for small hepatocellular carcinoma. PLoS ONE 2013;8:e79854.

51 Klein J, Dawson LA, Jiang H, Kim J, Dinniwell R, Brierley J, Wong R, Lockwood G, Ringash J: Prospective longitudinal assessment of quality of life for liver cancer patients treated with stereotactic body radiation therapy. Int J Radiat Oncol Biol Phys 2015;93:16-25.

52 Son SH, Choi BO, Ryu MR, Kang YN, Jang JS, Bae SH, Yoon SK, Choi IB, Kang KM, Jang HS: Stereotactic body radiotherapy for patients with unresectable primary hepatocellular carcinoma: dose-volumetric parameters predicting the hepatic complication. Int J Radiat Oncol Biol Phys 2010;78:1073-1080.

53 Culleton S, Jiang H, Haddad CR, Kim J, Brierley J, Brade A, Ringash J, Dawson LA: Outcomes following definitive stereotactic body radiotherapy for patients with Child-Pugh B or C hepatocellular carcinoma. Radiother Oncol 2014;111:412-417.

54 Huertas A, Baumann AS, Saunier-Kubs F, Salleron J, Oldrini G, Croisé-Laurent V, Barraud H, Ayav A, Bronowicki JP, Peiffert D: Stereotactic body radiation therapy as an ablative treatment for inoperable hepatocellular carcinoma. Radiother Oncol 2015;115:211-216.

55 Huang WY, Jen YM, Lee MS, Chang LP, Chen CM, Ko KH, Lin KT, Lin JC, Chao HL, Lin CS, Su YF, Fan CY, Chang YW: Stereotactic body radiation therapy in recurrent hepatocellular carcinoma. Int J Radiat Oncol Biol Phys 2012;84:355-361.

56 Andolino DL, Johnson CS, Maluccio M, Kwo P, Tector AJ, Zook J, Johnstone PA, Cardenes HR: Stereotactic body radiotherapy for primary hepatocellular carcinoma. Int J Radiat Oncol Biol Phys 2011;81:e447-e453.

57 Seo YS, Kim MS, Yoo SY, Cho CK, Choi CW, Kim JH, Han CJ, Park SC, Lee BH, Kim YH, Lee DH: Preliminary result of stereotactic body radiotherapy as a local salvage treatment for inoperable hepatocellular carcinoma. J Surg Oncol 2010;102:209-214.

58 Kwon JH, Bae SH, Kim JY, Choi BO, Jang HS, Jang JW, Choi JY, Yoon SK, Chung KW: Long-term effect of stereotactic body radiation therapy for primary hepatocellular carcinoma ineligible for local ablation therapy or surgical resection. Stereotactic radiotherapy for liver cancer. BMC Cancer 2010;10:475.

59 Keane FK, Tanguturi SK, Zhu AX, Dawson LA, Hong T: Radiotherapy for liver tumors. Hepatic Oncol 2015;2:133-146. DOI 10.2217/hep.15.7

60 Hong TS, Wo JY, Yeap BY, Ben-Josef E, McDonnell EI, Blaszkowsky LS, Kwak EL, Allen JN, Clark JW, Goyal L, Murphy JE, Javle MM, Wolfgang JA, Drapek LC, Arellano RS, Mamon HJ, Mullen JT, Yoon SS, Tanabe KK, Ferrone CR, Ryan DP, DeLaney TF, Crane CH, Zhu AX: A multi-institutional phase II study of high dose hypofractionated proton beam therapy in patients with localized, unresectable hepatocellular carcinoma and intrahepatic cholangiocarcinoma. J Clin Oncol 2015; (In press).

61 Llovet JM, Real MI, Montaña X, Planas R, Coll S, Aponte J, Ayuso C, Sala M, Muchart J, Solà R, Rodés J, Bruix J, Barcelona Liver Cancer Group: Arterial embolisation or chemoembolisation versus symptomatic treatment in patients with unresectable hepatocellular carcinoma: a randomised controlled trial. Lancet 2002;359:1734-1739.

62 Llovet JM, Bruix J: Systematic review of randomized trials for unresectable hepatocellular carcinoma: Chemoembolization improves survival. Hepatology 2003;37:429-442.

63 Cammà C, Schepis F, Orlando A, Albanese M, Shahied L, Trevisani F, Andreone P, Craxì A, Cottone M: Transarterial chemoembolization for unresectable hepatocellular carcinoma: meta-analysis of randomized controlled trials. Radiology 2002;224:47-54.

64 Lo CM, Ngan H, Tso WK, Liu CL, Lam CM, Poon RT, Fan ST, Wong J: Randomized controlled trial of transarterial lipiodol chemoembolization for unresectable hepatocellular carcinoma. Hepatology 2002;35:11641171.

65 Seong J, Lee IJ, Shim SJ, Lim H, Kim TH, Kim JH, Jang HS, Kim MS, Chie EK, Kim JH, Nam TK, Lee HS, Han CJ: A multicenter retrospective cohort study of practice patterns and clinical outcome on radiotherapy for hepatocellular carcinoma in Korea. Liver Int 2009;29:147-152.

66 Choi C, Koom WS, Kim TH, Yoon SM, Kim JH, Lee HS, Nam TK, Seong J: A prospective phase 2 multicenter study for the efficacy of radiation therapy following incomplete transarterial chemoembolization in unresectable hepatocellular carcinoma. Int J Radiat Oncol Biol Phys 2014;90:1051-1060.

67 Llovet JM, Bustamante J, Castells A, Vilana R, Ayuso MC, Sala M, Brú C, Rodés J, Bruix J: Natural history of untreated nonsurgical hepatocellular carcinoma: rationale for the design and evaluation of therapeutic trials. Hepatology 1999;29:62-67. 
68 Salem R, Lewandowski RJ, Mulcahy MF, Riaz A, Ryu RK, Ibrahim S, Atassi B, Baker T, Gates V, Miller FH, Sato KT, Wang E, Gupta R, Benson AB, Newman SB, Omary RA, Abecassis M, Kulik L: Radioembolization for hepatocellular carcinoma using Yttrium-90 microspheres: a comprehensive report of long-term outcomes. Gastroenterology 2010;138:52-64.

69 Sugahara S, Nakayama H, Fukuda K, Mizumoto M, Tokita M, Abei M, Shoda J, Matsuzaki Y, Thono E, Tsuboi K, Tokuuye K: Proton-beam therapy for hepatocellular carcinoma associated with portal vein tumor thrombosis. Strahlenther Onkol 2009;185:782-788.

70 Choi BO, Choi IB, Jang HS, Kang YN, Jang JS, Bae SH, Yoon SK, Chai GY, Kang KM: Stereotactic body radiation therapy with or without transarterial chemoembolization for patients with primary hepatocellular carcinoma: preliminary analysis. BMC Cancer 2008;8:351.

71 Xi M, Zhang L, Zhao L, Li QQ, Guo SP, Feng ZZ, Deng XW, Huang XY, Liu MZ: Effectiveness of stereotactic body radiotherapy for hepatocellular carcinoma with portal vein and/or inferior vena cava tumor thrombosis. PLoS ONE 2013;8:e63864.

72 Huang YJ, Hsu HC, Wang CY, Wang CJ, Chen HC, Huang EY, Fang FM, Lu SN: The treatment responses in cases of radiation therapy to portal vein thrombosis in advanced hepatocellular carcinoma. Int J Radiat Oncol Biol Phys 2009;73:1155-1163.

73 Chuma M, Taguchi H, Yamamoto Y, Shimizu S, Nakanishi M, Ogawa K, Sho T, Horimoto H, Kobayashi T, Nakai M, Terashita K, Sakuhara Y, Abo D, Tsukuda Y, Tsunematsu S, Hige S, Kato M, Shirato H, Asaka M: Efficacy of therapy for advanced hepatocellular carcinoma: intra-arterial 5-fluorouracil and subcutaneous interferon with image-guided radiation. J Gastroenterol Hepatol 2011;26:1123-1132.

74 Rim CH, Yang DS, Park YJ, Yoon WS, Lee JA, Kim CY: Effectiveness of high-dose three-dimensional conformal radiotherapy in hepatocellular carcinoma with portal vein thrombosis. Jpn J Clin Oncol 2012;42:721729.

75 Wang X, Krishnan S, Zhang X, Dong L, Briere T, Crane CH, Martel M, Gillin M, Mohan R, Beddar S: Proton radiotherapy for liver tumors: dosimetric advantages over photon plans. Med Dosim 2008;33:259-267.

76 Abe T, Saitoh J, Kobayashi D, Shibuya K, Koyama Y, Shimada H, Shirai K, Ohno T, Nakano T: Dosimetric comparison of carbon ion radiotherapy and stereotactic body radiotherapy with photon beams for the treatment of hepatocellular carcinoma. Radiat Oncol 2015;10:187.

77 Nakayama H, Sugahara S, Tokita M, Fukuda K, Mizumoto M, Abei M, Shoda J, Sakurai H, Tsuboi K, Tokuuye K: Proton beam therapy for hepatocellular carcinoma: the University of Tsukuba experience. Cancer 2009;115:5499-5506.

78 Bush DA, Kayali Z, Grove R, Slater JD: The safety and efficacy of high-dose proton beam radiotherapy for hepatocellular carcinoma: a phase 2 prospective trial. Cancer 2011;117:3053-3059.

79 Clinicaltrials.gov identifier NCT01730937. Accessed September 30, 2015.

80 Clinicaltrials.gov identifier NCT00857805. Accessed August 1, 2015.

81 Clinicaltrials.gov identifier NCT01135056. Accessed April 1, 2015. 